\title{
Landslide Loss and Damage in Sindhupalchok District, Nepal: Comparing Income Groups with Implications for Compensation and Relief
}

\author{
Kees van der Geest ${ }^{1}$
}

Published online: 12 June 2018

(C) The Author(s) 2018

\begin{abstract}
The 2014 Jure landslide in Sindhupalchok District, Nepal, caused significant loss and damage to ecosystems and livelihoods in the area. In the direct aftermath of the landslide, several disaster loss assessments were conducted, with the aim of counting casualties, injured people, and damaged houses and infrastructure. Although useful and necessary in their own right, such rapid assessments do not reveal the true extent and significance of the losses and damages that people in disaster areas face, including their monetary value. We address this gap, based on a comprehensive household survey $(N=234)$, as well as other, qualitative research tools. Our results highlight the importance of differentiating between loss and damage in absolute monetary terms as opposed to losses relative to annual income. We find a stark contrast between the high absolute losses incurred by nonpoor households, and the high relative losses - up to 14 times their annual income-experienced by poor households. These results have important implications for policy that addresses loss and damage, not only of landslides but also of other disasters. Loss and damage assessments need to take the livelihood characteristics of affected households into account to identify and support those most in need of compensation and relief.
\end{abstract}

Keywords Compensation and relief - Impact assessment · Landslides · Loss and damage analysis $\cdot$ Nepal

Kees van der Geest

geest@ehs.unu.edu

1 United Nations University Institute for Environment and Human Security, Platz der Vereinten Nationen 1, 53113 Bonn, Germany

\section{Introduction}

On 2 August 2014, a major landslide struck in a denselypopulated area of Nepal's Sindhupalchok District, $80 \mathrm{~km}$ northeast of Kathmandu. With a death-toll of 156, it was one of the deadliest landslides in Nepal history. The landslide extended $1.26 \mathrm{~km}$ from head to toe and was $0.81 \mathrm{~km}$ wide at the bottom. It destroyed all land, houses, properties, and other infrastructure along the failure surface and created a 55 m-high dam in the Sunkoshi River (Fig. 1). This debris dam led to the formation of a lake, which inundated houses, farms, and a hydropower plant for $3 \mathrm{~km}$ upstream from the base of the landslide. There was a high risk of an outburst flood, which necessitated the evacuation of settlements downstream. The Araniko Highway-Nepal's only road connection to China-was severely damaged, with nation-wide repercussions for trade and general mobility. During the days and weeks after the landslide, army engineers forced openings in the dam through digging and controlled blasting to reduce inundation and flood risk.

\subsection{The Concept of Loss and Damage}

"Loss and damage" is an emerging topic in climate change negotiations, research, policy, and the implementation of climate change action (Roberts and Pelling 2016). Losses and damages can result from insufficient efforts to achieve disaster risk reduction, inadequate coping and adaptation strategies, and unavoidable impacts (Roberts et al. 2014). Often portrayed as a future threat, loss and damage is also a present-day reality that vulnerable people in many parts of the world already face (van der Geest and Warner 2015). The concept of loss and damage connects the fields of climate change adaptation and disaster risk reduction. It 


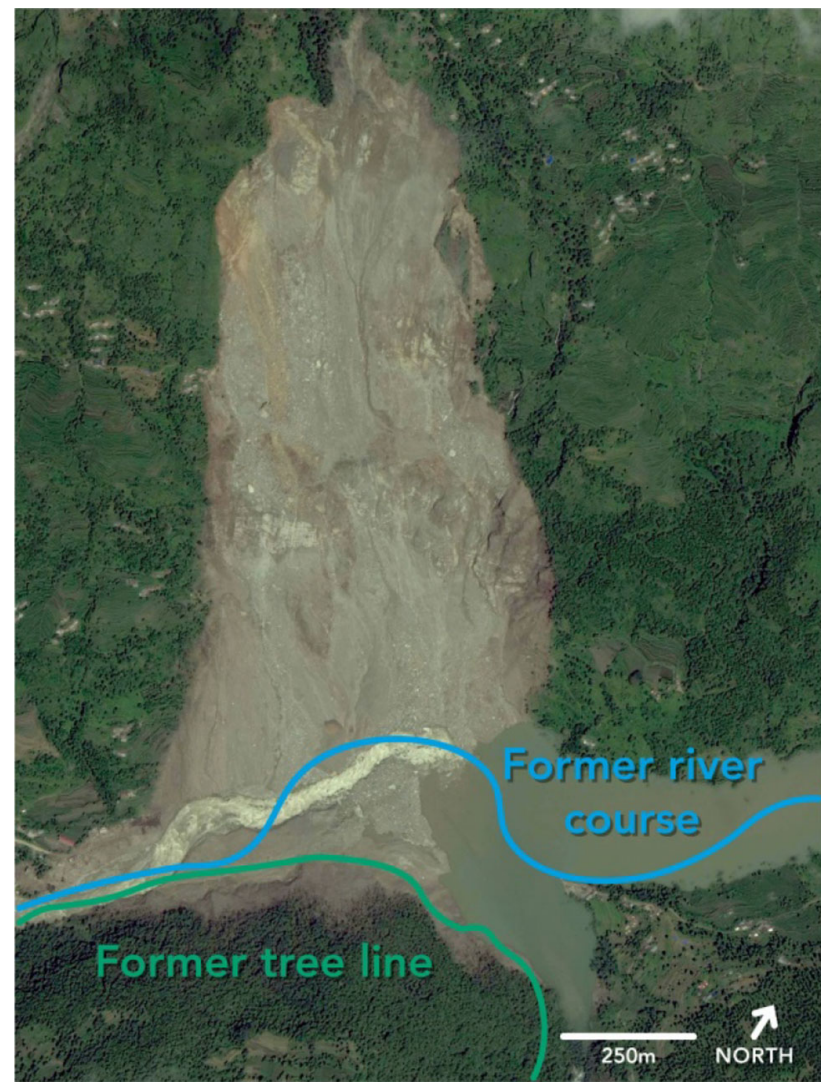

Fig. 1 The extent of the 2 August 2014 Jure landslide, indicating the former river course and tree line. Source Google Earth. Graphic design: Aileen Orate

also relates to questions on liability and compensation for climate change-induced losses and damages. With the emergence of loss and damage in climate negotiations, particularly since the establishment of the Warsaw International Mechanism (WIM), the issue of liability and compensation for loss and damage incurred due to extreme weather events has gained international importance (Boyd et al. 2017).

The concept of loss and damage is equally relevant in the global political discourse and in empirical research on a local level, albeit in different ways. Loss and damage in global discussions can be described as the impacts of climate change that are not avoided by mitigation and adaptation efforts (Roberts and Huq 2015). On the local level, loss and damage refers to those impacts of climate-related stressors that are not avoided by coping and adaptation (Warner and van der Geest 2013). In other words, global discussions surrounding loss and damage are generally more concerned to reduce greenhouse gas emissions and provide adaptation finance, while local empirical work looks at how climate impacts affect vulnerable people; studies the measures they adopt to prevent impacts (adaptation); and investigates what they do to deal with impacts that they are not able to prevent (coping).
Scale plays an important role in the choice of a working definition of loss and damage in academic work (UNEP 2016). For example, in local assessments of loss and damage from climate-related disasters, the reduction of global greenhouse gas emission is not directly relevant. Vice versa, local measures to cope with the impacts of disasters have little impact on global policy dialogues on loss and damage. Due to these differences, the concept of loss and damage needs to be separately defined for a global and a local context. As this article focusses on a local context, and studies losses and damages for a particular event, it uses the following definition: Loss and damage refers to adverse effects of climate-related stressors resulting from insufficient capacity to reduce the risks associated with climate-related stressors, to cope with impacts of climate-related events, and to adapt to climatic changes.

The concept of loss and damage is closely related to the concept of climate change impacts. Although there is much overlap between the two terms, they are not the same: loss and damage goes beyond analyzing impacts by emphasizing that currently many avoidable impacts are not being avoided due to adaptation constraints, which often are caused by limited financial resources (Agrawala and Fankhauser 2008; Bauer 2013). Beyond financial resource constraints, Adger et al. (2009, p. 338) drew attention to four "meta domains" that categorize adaptation limits into "ethics (how and what we value), knowledge (how and what we know), risk (how and what we perceive) and culture (how and why we live)." These meta domains are relevant in discussions surrounding loss and damage and show how the concept goes beyond simply analyzing impacts from climate change. Next to adaptation constraints, loss and damage recognizes that there are limits to adaptation (Dow et al. 2013). Due to these limits, some impacts cannot be avoided even with a hypothetical, complete removal of adaptation constraints and the uptake of all conceivable adaptation measures. Loss and damage beyond adaptation limits need to be addressed retroactively.

\subsection{Climate Change Attribution}

To what extent can specific extreme events, such as landslides, be attributed to anthropogenic climate change? This is an important question in the context of international climate change negotiations (Parker et al. 2017). The attribution question will gain more importance in the future, when victims of climate change impacts start suing polluters, such as in the case of a Peruvian farmer who recently sued a German energy company (Lawson 2017). Climate scientists are quite able to attribute certain slowonset processes, such as sea level rise and glacial retreat, to 
global warming. But attribution is much more complex for sudden-onset extreme events (James et al. 2014).

Landslides are common in the Hindu Kush Himalayan region, mainly due to weak geological formations and local topography, combined with unsustainable land use and extreme rainfall events (Dahal and Hasegawa 2008). The 2014 Jure landslide, whose impacts we studied for the present article, was preceded by 2 days of torrential rainfall (141 mm), which triggered the landslide. At a global level the occurrence of extreme rainfall events is projected to increase in the twenty-first century due to climate change (IPCC 2012). Scientific work that looks at the effects of climate change on the Himalaya region has shown that the effects of climate change are primarily visible in increased regional average temperatures of $0.01{ }^{\circ} \mathrm{C}$ per year (Sharma et al. 2009), and a greater variability of precipitation (Mirza 2010). Nepal's increasing temperatures will elevate the region's snowline, lead to greater amounts of meltwater in the short term, and perpetuate the risk of inundation and floods. Greater amounts of meltwater cause lubrication of hillsides, which could promote slope failure and also increase landslide risk (Sharma et al. 2009). There is little research, however, that attributes the occurrence of landslides directly to climate change (Huggel et al. 2012), and a recent rainfall data analysis by the Department of Hydrology and Meteorology of Nepal's Ministry of Population and Environment shows no increase in the number of extreme rainfall events between 1971 and 2014 (Government of Nepal 2017). In sum, existing research at a global level suggests that climate change has the potential to increase landslide risk through its influence on the frequency and magnitude of extreme rainfall events. The landslide whose effects we studied was preceded by 2 days of torrential rainfall, but there is no evidence that climate change increased the probability of extreme rainfall in this case because no increase in the number of extreme rainfall events is discernible in Nepal.

The present study about a particular landslide in Nepal was conducted with the aim of advancing and testing methods that assess loss and damage in vulnerable communities (van der Geest and Schindler 2017). Because the focus of a loss and damage assessment is on the consequences of disasters, for this purpose, it is of less importance whether the disaster can be attributed to climate change. This is different in legal cases when loss and damage assessments are used to prepare a claim for monetary compensation (Huggel et al. 2016).

\subsection{Expressing Loss and Damage in Monetary Terms}

The emerging empirical literature on loss and damage from climate events has been hesitant to express these impacts in monetary terms (Warner et al. 2012, 2013; Bauer 2013; Kusters and Wangdi 2013). Our article attempts this quantification, but it highlights the difference between absolute and relative losses and damages. Taking this difference into account shows that viewing losses and damages relative to annual income represents the impacts of disasters far more realistically.

These findings in a local research context gain relevance in a global view on the evaluation of and compensation for losses and damages from climate-related disasters. Using monetary losses as a guideline against which to assess loss and damage implies that poorer people and regions would receive far less compensation than wealthier people and regions when, for example, a cyclone destroys houses and property, simply because the assets of the wealthy are worth more. To address this imbalance, we suggest that the primary focus of evaluation, and by extension also compensation efforts for loss and damage, should be on assessing what victims of disasters would need to rebuild a sustainable livelihood, rather than focusing on the monetary equivalent of their losses and damages.

A comparison of estimated damage caused by natural hazards in Bangladesh and the United States illustrates this point. When Cyclone Sidr hit Bangladesh in 2007, it made millions of people homeless and disrupted livelihoods in large parts of the country. The number of casualties was estimated at 3406 and the total economic damage at USD 1.7 billion, which amounted to $3 \%$ of national GDP (Paul and Dutt 2010; Nadiruzzaman and Wrathall 2015). By contrast, Hurricane Sandy caused "only" 72 direct deaths in the United States (Blake et al. 2013), but estimates of total economic damage ranged from approximately USD 50 billion (Blake et al. 2013; Kryvasheyeu et al. 2016) to more than USD 100 billion (Kunz et al. 2013). If there had been a global fund for compensating loss and damage from climate-induced disasters, a vastly higher amount would have gone to wealthy parts of the world while the most vulnerable countries would receive much less.

\subsection{Research Question and Structure}

This article answers the following research question: How did the losses and damages caused by the Jure landslide in 2014 vary between poor and nonpoor households, and what are the implications for compensation and relief? The article is structured as follows. Sections 2 and 3 introduce the data-gathering methods, the study area, and the survey population. In the results section, losses and damages are analyzed by type and monetary value. The last element of the results section represents the core of the article and analyzes loss and damage by income group. The discussion section continues by giving the authors' views of the relevance of the results for policy debates about compensation 
and relief. Finally, the most important aspects of this article are revisited in the conclusion.

\section{Methods}

The findings in this article are primarily based on a household survey that combines quantitative and qualitative data from 234 respondents. Beyond the household survey, the fieldwork team conducted expert interviews and focus group discussions. Secondary sources and eye witness accounts were also consulted to triangulate the survey findings for accuracy. In contrast to other loss and damage assessments that focus more narrowly on quantifying lives lost, people displaced, and damage to tangible assets (for example, Khanal and Gurung 2014; Shrestha et al. 2014; Sapkota 2017), this people-centered approach allows for a more need-based perspective that goes beyond a simple stocktaking of disaster losses and thus yields more meaningful results.

\subsection{Household Questionnaire}

The household questionnaire is the main data source for this article. After a 3-day training by the principal investigator, a team of five enumerators interviewed 234 respondents between 26 March and 6 April 2015. Each questionnaire encompassed 13 pages and took 45-60 min to complete. The questionnaire struck a balance between capturing quantifiable elements and allowing a qualitative understanding of loss and damage. Key topics, such as landslide impacts, were introduced with open-ended questions and were followed by more detailed, close-ended questions that quantified losses and damages and the effectiveness of household risk management.

The questionnaire itself was based on a template developed by the principal investigator as part of a handbook for assessing loss and damage in vulnerable communities (van der Geest and Schindler 2017). The questionnaire consists of three parts. Part 1 inquires about basic sociodemographic data and poses questions about peoples' livelihood activities, income, assets, and food security. Part 2 assesses the losses and damages that respondents incurred and examines the effectiveness and costs of the preventive and coping measures they adopted. In the third part, respondents shared their perceptions of vulnerability, as well as their recommendations for future actions that could be taken by organizations or the government to better protect people against landslide impacts.

\subsection{Survey Sample}

The expert interviews held in Kathmandu and the informal interviews conducted upon arrival in the landslide area revealed that impacts varied greatly by location. The consequences downstream were different from those incurred upstream, and varied depending on proximity to the area that was covered by the landslide and its debris. Based on this, the team decided to purposely select survey areas around the landslide zone that represented the different impact types (Fig. 2). Within those designated areas, all households were interviewed. The only exception was the cluster 'Upstream', where the first interviews we conducted showed that the effects of the landslide had been very limited, so that it was decided to move on to other locations without interviewing everyone in that cluster.

\section{Study Area and Population}

This section provides a brief description of the study area and outlines sociodemographic characteristics of the surveyed households.

\subsection{Study Area}

The study area lies in a valley surrounded by hills and mountains in the district of Sindhupalchok, which lies in the Central Development Region of Nepal (Fig. 3). The district spans an area of $2542 \mathrm{~km}^{2}$ and contains 79 Village Development Committees, the lowest administrative unit in Nepal. Sindhupalchok is located to the northeast of Kathmandu and borders on Tibet, China to the north. The Araniko Highway that was destroyed by the landslide runs through the district and the landslide area is the only road connection between Nepal and China. The dense settlement of the area and the destruction of the highway meant that the effects of the landslide were felt far beyond Sindhupalchok District.

\subsection{Survey Population}

The household interviews were mostly held with the household head $(67 \%)$. In other cases, the head's spouse (27\%), or child $(6 \%)$ was interviewed. Selecting some respondents who were not considered the head of the household was deliberate, to avoid a male bias in the research results. If only household heads had been interviewed, $82 \%$ of respondents would have been male, whereas the sample now contains $47 \%$ of responses from female interviewees.

Nearly $90 \%$ of respondents were married, and the clear majority of surveyed households was Hindu (around 87\%). 
Fig. 2 Spatial distribution of the respondent households. Source Google Earth. Graphic design: Aileen Orate

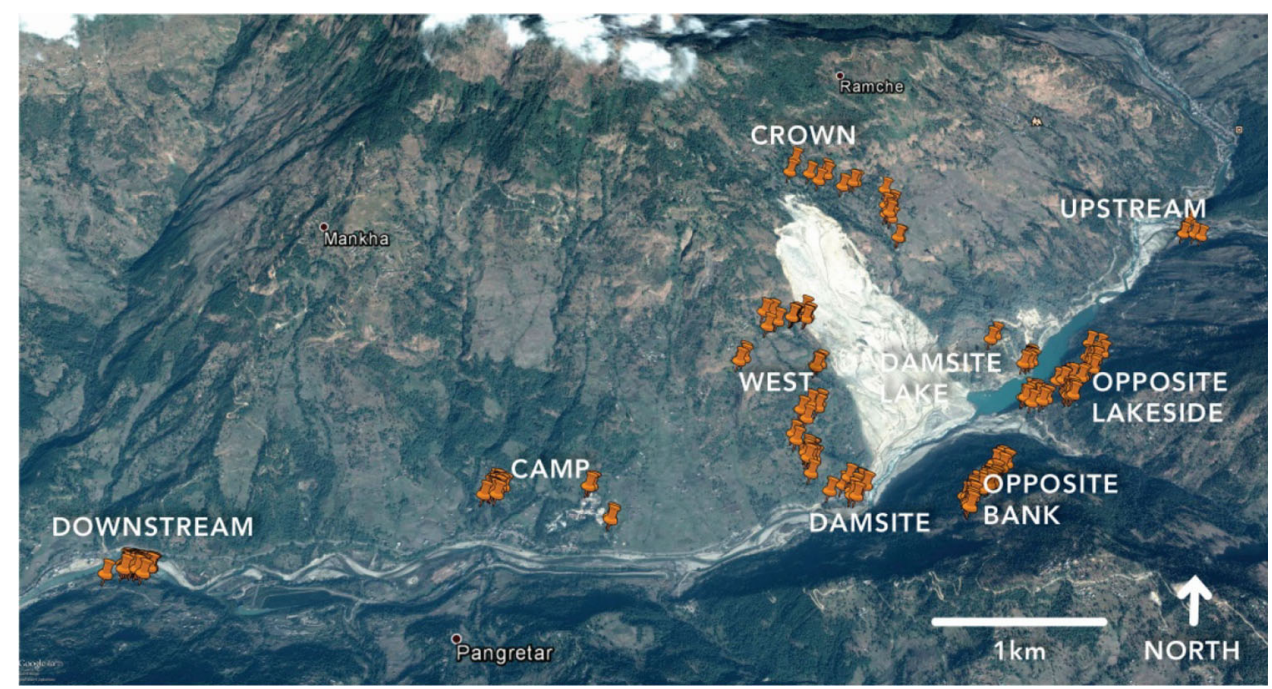

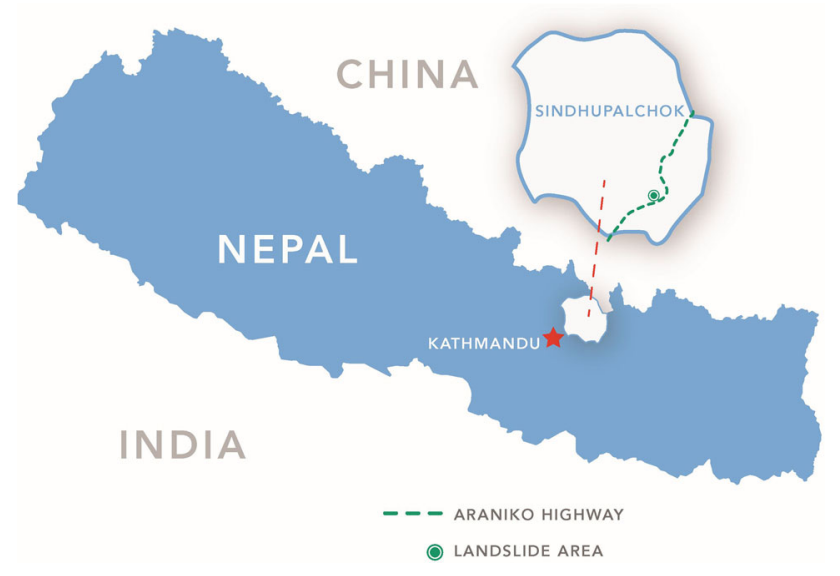

Fig. 3 Location of Sindhupalchok District and landslide area in Nepal. Source Authors' own; design by Aileen Orate

Nearly $95 \%$ of respondents indicated they were born in the district. Other respondents came from elsewhere in Nepal, but never from outside the country. The level of formal education among respondents was generally low. Approximately $31 \%$ had only completed a literacy course, and $28 \%$ had no formal education at all. About a fifth $(21 \%)$ had attained primary education, and $17 \%$ reached lower secondary education. Higher secondary education was completed by only $3 \%$ of the sample.

Most surveyed households engaged in three or more economic activities simultaneously (94\%). A majority combined subsistence-oriented farming with nonfarm activities and sometimes remittances for cash income. In total, $99 \%$ of the sample were farmers. As farming in the area is mostly subsistence-oriented, agriculture yielded little monetary revenue. Nonfarm activities (84\%) and remittances (45\%) generated the largest cash income. Other sources of income, such as pensions and rent, as well as fishing, were rare and not lucrative. In terms of living conditions, $95 \%$ of sampled households owned the house they lived in. Houses mostly had roofs covered with iron sheets, walls made from stone or mud, and earthen floors. Most respondents were satisfied with the quality of their house (87\%), but thought that it was in a risk-prone area $(75 \%)$. In sum, the average respondent was a married farmer of Hindu faith, living in his village of birth, with little to no formal education.

\section{Results}

This section outlines how severely households in the landslide area were impacted by the landslide, followed by a comparison of losses and damages for different income groups. The latter shows that nonpoor households lost most in absolute terms, while poor households were more severely affected relative to their annual per capita income.

\subsection{Landslide Impacts}

The landslide severely impacted household assets and the natural environment in the area. Figure 4 shows the proportion of households that incurred the different types of losses and damages (blue bars), and the average monetary value that was attributed to them by the respondents (yellow bars). Most households reported losses and damages to crops. Soil or land was impacted almost as frequently, but led to the most substantial costs (over USD 25,000 on average), as lost soil or land entails the permanent loss of the basis for people's livelihoods.

Next to material losses, noneconomic losses also played a substantial role in the aftermath of the landslide. First, one in 10 interviewed households lost a household member in the event. Second, respondents experienced severe 
Fig. 4 Proportion of affected households and mean cost by impact type

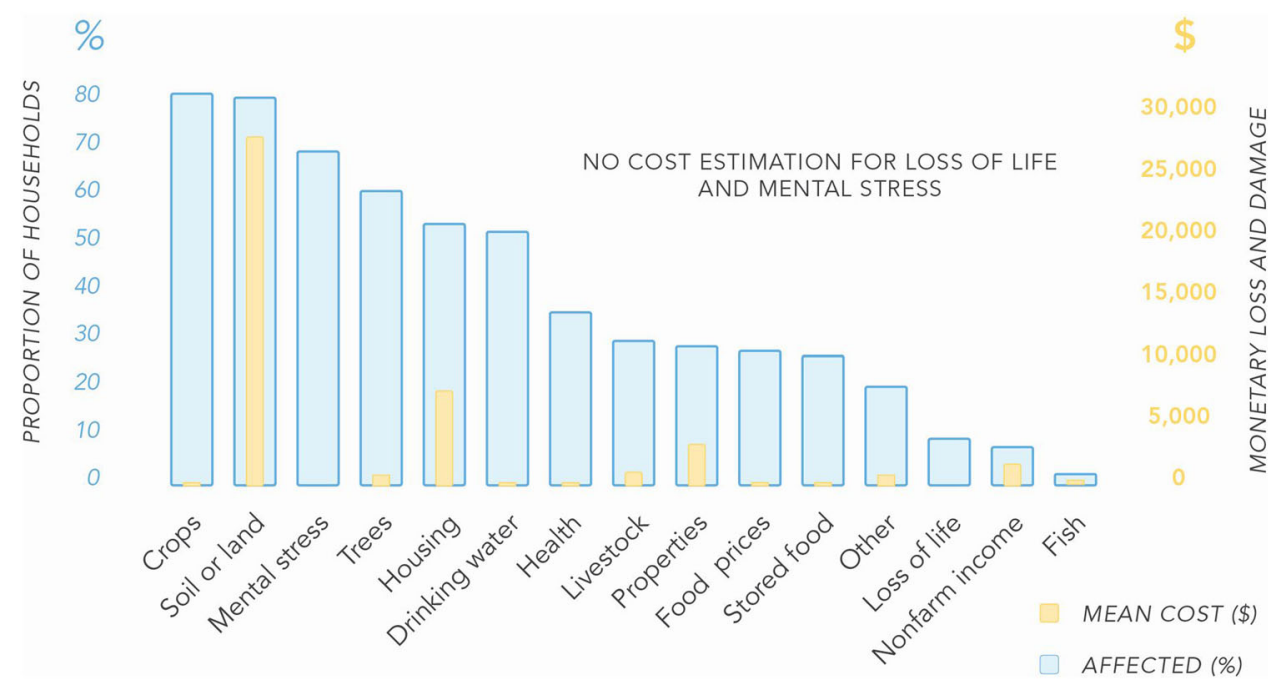

mental stress, as the landslide caused trauma about losses and fear of new landslides. Mental stress could not be evaluated monetarily, as an accurate and context-independent method of doing so is yet to be invented (Serdeczny et al. 2016). Accordingly, respondents would typically declare that no amount of money or compensation could bring back their loved ones and return them to the level of well-being they had before the landslide.

Among the losses and damages for which respondents were able to estimate the monetary value, loss of land was responsible for more than half of the costs. The accurateness of the land loss estimates in monetary terms was validated with local experts, considering the size of the land and the location relative to the Araniko Highway (van der Geest and Schindler 2016). Figure 5 illustrates the incisive effect that these losses had on the livelihood of respondents. The figure shows that $79 \%$ of households incurred land-loss because of the landslide. Most respondents estimated the losses and damages to be in the USD $1000-10,000$ bracket (30\%), while $25 \%$ lost between USD 10,000 and 50,000, and $12 \%$ reported to have lost land valued at more than USD 50,000. About a fifth of respondents $(21 \%)$ sustained no losses or damages from the landslide. Apart from its monetary value, land loss also has profound social, cultural, and other noneconomic implications that cannot be expressed in money.

As shown in Fig. 6, almost all respondents were impacted by the landslide in at least one way (99\%). Ten or more types of impacts were experienced by $11 \%$. The mean number of impacts sustained by households was 5.8, and the median was 5 .

\subsection{Loss and Damage by Income Group}

This section goes into more detail about the difference between absolute and relative losses and damages. Although vulnerability and poverty are different concepts, and one does not necessarily imply the other (Chambers 1989), the poor tend to be more vulnerable to disasters than the nonpoor (Blaikie et al. 2003). Many factors that perpetuate vulnerability, especially economic vulnerability, are directly associated with poverty. Other dimensions of vulnerability, for example social, physical, and cultural (Birkmann et al. 2013), also correlate with poverty, albeit to varying degrees.

Based on the survey data and the distribution within the sample, Fig. 7 divides respondents into three groups: households earning less than USD 1000 per year, households earning more than USD 2000 per year, and the households in between. The green bars show that the absolute median household-level losses and damages in monetary terms of nonpoor households were much higher than those of poor households.

By contrast, the blue bars represent loss and damage as a ratio of household income. This depiction gives a sense of how deeply households were truly affected by the event. The median value of losses among households in the lowest income group amounted to 14 times their median annual income, while the median losses among the richest households in the sample were equal to three times their median annual income. Taking a relative perspective on the value of losses and damages reveals the true severity of impacts for households in different income groups. Next to having experienced more severe impacts, the poor households' low income means that the poor are less likely to ever regain their prelandslide status quo. 


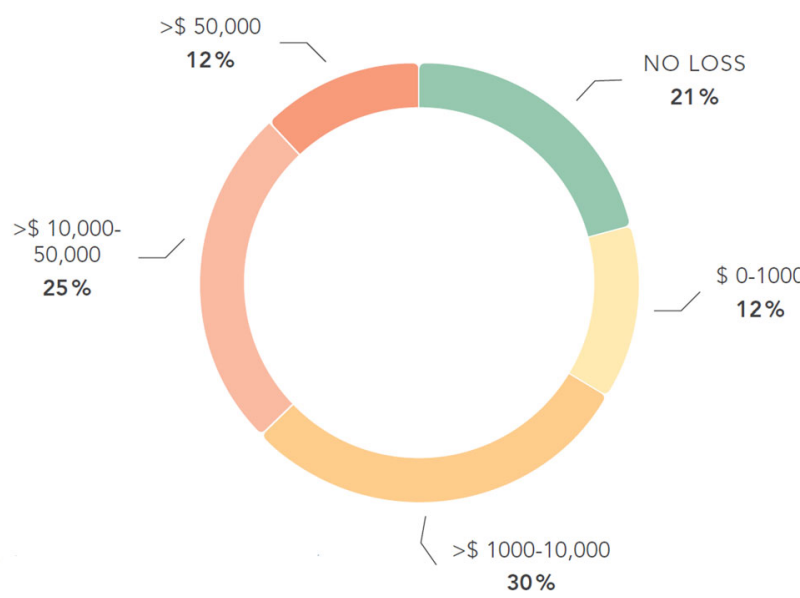

Fig. 5 Value of land losses incurred by households as a result of the 2 August 2014 Jure landslide in Sindhupalchok District, Nepal

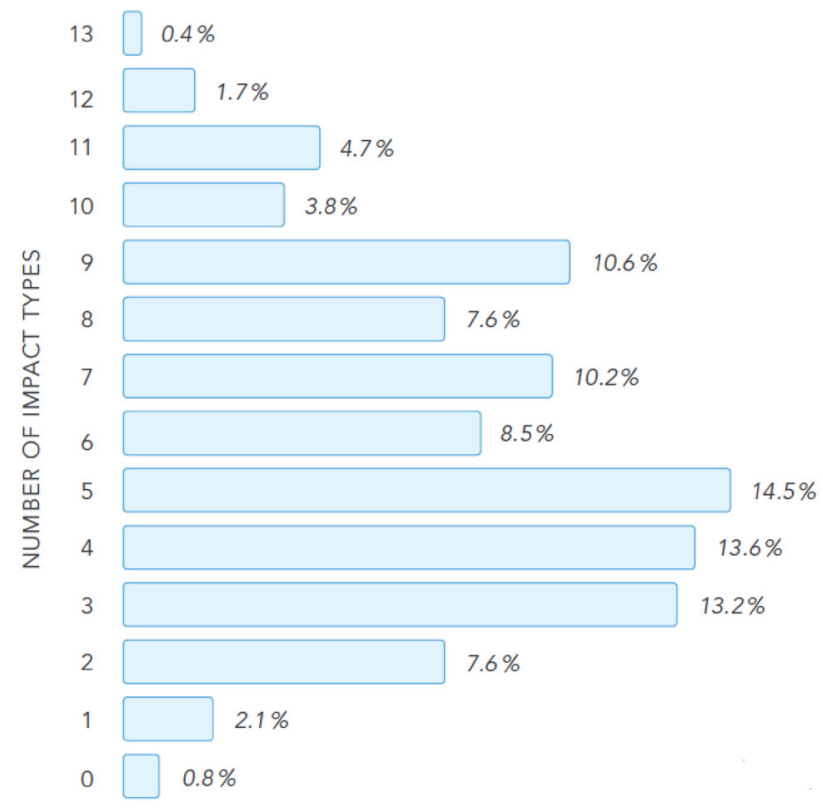

PROPORTION OF HOUSEHOLDS

Fig. 6 Number of impact types experienced by households as a result of the 2 August 2014 Jure landslide in Sindhupalchok District, Nepal

\subsection{Provision of Compensation and Relief}

In the aftermath of the Jure landslide, the government and nongovernmental organizations arrived in the area to provide relief in the form of monetary compensation and inkind support such as food aid, drinking water, blankets, and building materials. Relief was provided by the government and the District Development Commission, Village Development Committees, NGOs (for example, the Red Cross, the Federation of Nepalese Chambers of Commerce and Industry, and the Srijansil children welfare

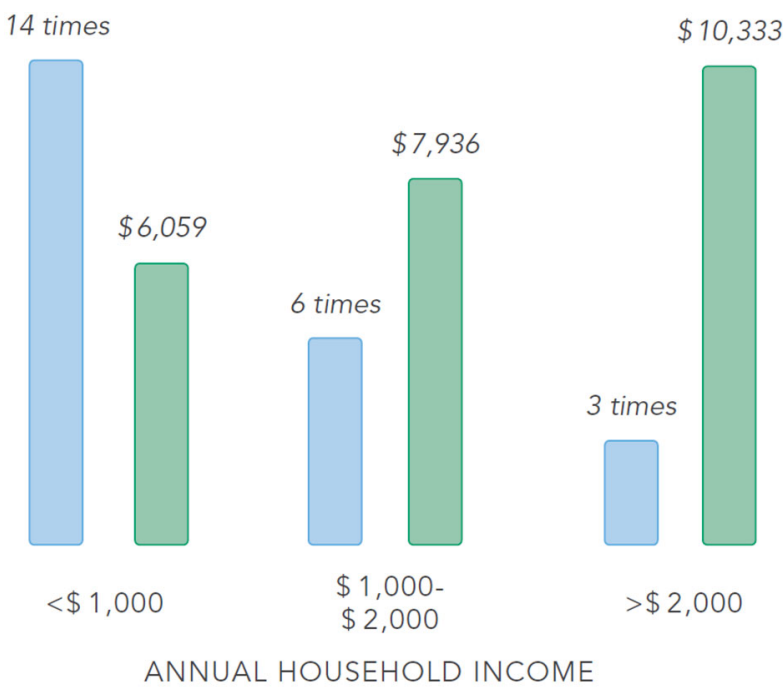

- LOSS AND DAMAGE RELATIVE TO ANNUAL INCOME

- LOSS AND DAMAGE (\$) - MEDIAN

Fig. 7 Loss and damage in USD and as proportion of annual income

organization), political parties, a bank, the army, religious organizations, and the police.

For the distribution of relief among affected households, the District Disaster Relief Committee divided households in three categories based on the loss and damage to house and land they had incurred. Households were given a red card when their house and land were destroyed, a yellow card for severe damages to house and land, and a green card in the case of moderate damage. The Village Development Committees coordinated a relief fund that was created for the support of landslide victims. It was funded by donations from organizations on the one hand and individuals, such as business people and international migrants, on the other. NGOs often helped via in-kind donations and support. The Red Cross erected a camp to harbor displaced people, who continued to receive support at the time of the fieldwork for this study, 7 months after the landslide. A government report specified that 384 persons received in-kind relief material in the aftermath of the disaster (Government of Nepal 2014). The government also paid a fixed amount of 40,000 rupees (approximately USD 400) to relatives of the 156 people who died in the landslide to cover funeral expenses.

Despite these efforts, the findings of our study show that the actual number of affected households far exceeded those who were mentioned on the list of affected people. The list used a narrow definition of who was a victim of the landslide to categorize the affected, which was solely based upon loss of life within a household, or the destruction of homes and land. By contrast, our research shows that $99 \%$ of the respondent households were affected by the 
landslide and almost $90 \%$ incurred three or more impact types. Many of these households did not receive any support because their losses and damages were in other categories than "loss of life," "loss of land," and "damage to housing."

The research team organized two focus group discussions-one with men and one with women-in which participants talked about the effectiveness of aid. The general tendency was that people were grateful for the support they received, but they were also quite critical about its effectiveness and they felt that aid often did not reach the neediest. Another pattern was that focus group participants were more positive about the support of NGOs than that of the government.

\section{Discussion}

Perspective plays an important role in estimating the severity of impacts from disasters. The findings presented here illustrate how absolute loss and damage assessments often fail to reflect adequately the situation in which affected households find themselves and to take into account their prospect for post-disaster recovery (Merz et al. 2010). The true severity of impacts depends much less on their monetary value itself, but rather on how their monetary value relates to the resources at a household's disposal. While it seems straightforward to conclude that any monetary loss is more severe the poorer the household that experiences it, relative loss and damage assessments are scarce. This is surprising, taking into account how crucial the role of impact assessment is for the payout of compensation money and the provision of relief goods.

The additional effort required to assess loss and damage in relative terms is a possible explanation for their scarcity. As our research shows, a focus on absolute loss and damage not only often inaccurately identifies those in greatest need of support, but also it actually produces opposite results. A focus on absolute monetary losses would channel most resources available for post-disaster support to households or regions that are the least vulnerable.

This article looks at the implications of absolute versus relative assessment of loss and damage for compensation and relief, but it is important to briefly highlight how these two types of support differ. Compensation implies liability and the rights to claim, and typically requires an absolute assessment of the monetary value of the losses. One could compare this with insurance payouts. Relief on the other hand, is more needs-based and is guided by humanitarian principles. This requires a loss and damage assessment that includes not just what people have lost, but also what people still have, and hence what they lack. The two support systems often coexist in post-disaster situations. If the financial resources available for compensation are enough, it makes sense to compensate all losses and damages and require just an absolute assessment of loss and damage in monetary terms. The situation is different when the funds are not enough to compensate for all losses. In such situations, we maintain that actual payout should be guided not only by the absolute losses (for example, a payout of $70 \%$ of the losses), but also by the poverty and vulnerability levels of those affected. Intuitively, perhaps it would be strange if wealthier households or regions get less payout from compensation or contingency funds if the value of their losses is higher. But from a humanitarian and needs-based perspective, and to facilitate post-disaster recovery, this would be the right approach. The example in the introduction of this article, which compared loss and damage from storms in Bangladesh and the United States, illustrates this point.

Hence, it is prudent to call for better practices to assess losses and damages from disasters in relative terms. The first option is to identify those in need based on households' estimate of the losses incurred and their annual income. The risk of incentivizing overstatements of loss and damage, however, as well as understatements of income may make this approach less desirable. Moreover, estimating household income in rural areas of developing countries is notoriously difficult (Greeley 1994). Instead, using locally validated proxies of wealth or a multidimensional vulnerability index (van der Geest and Warner 2015) could be more accurate and reliable. This also could be a relatively simple way to improve the adequacy of compensation payouts and relief distributions.

Payout of compensation for losses and distribution of relief could be based on a second option-what a household needs to sustainably recover from a disaster. Instead of focusing on what people have lost, the prerogative could be what people need to sustain their existence. Assessing what households still have, instead of what they have lost, could enable a needs-based distribution system where what a household receives is based on a predefined basket of items. This way, relief is detached from predisaster wealth and may even add a stimulus to the local economy, if items are purchased locally. Instead of exaggerating predisaster possessions, potential recipients may now be incentivized to understate what they still have to maximize what they receive. Especially gross misinformation would likely be significantly easier to detect, as a household's possessions are evidenced by their daily lives. Beyond institutional control, those in true need of relief may denounce profiteering households and thus provide an additional check on underreporting.

In some cases, compensation and relief may simply be unable to foster a sustainable recovery in situ. In this 
situation, providing options for resettlement to get out of harm's way may be more prudent than spending resources to restore the local predisaster status quo. But to accomplish resettlement also requires active consideration of noneconomic losses and damages (Serdeczny et al. 2016). Generally, the suggestions provided in this discussion section are by no means prescriptive, but are intended as a constructive contribution to an ongoing debate.

\section{Conclusion}

This article provides local evidence for a phenomenon that holds a warning for future, global discussions on the evaluation of loss and damage and the discourse on compensation that these entail (James et al. 2014; Burkett 2016). The people-centered approach that informed our results and conclusions paired qualitative research tools with in-depth quantitative survey data on livelihoods and landslide impacts. It contributes to the debates surrounding the evaluation of and the compensation for disaster losses by showing how loss and damage assessments relative to annual income tend to represent post-disaster needs more accurately than absolute loss and damage assessments. The results show that losses and damages incurred by poor households amounted to around USD 6000, which was 14 times those households' median annual income. This gives us an idea about how hard it will be for them to recover, and, indeed, many expressed the fear that they will never fully recover to their predisaster level of livelihood security. Nonpoor households lost more in absolute terms (more than USD 10,000), but much less in relative terms (three times their annual income). For this group, post-disaster recovery will also be a long process, but their prospects are clearly better.

For discussions on loss and damage valuation and compensation in the international climate change negotiation, these results have an important message: The people who are in direst need of support for survival and recovery are at risk of receiving the least because their losses and damages are lower in monetary terms. The findings provide a basis to question whether the currently prevalent approaches to assess loss and damage and provide compensation and relief should be revisited and expanded to include assessment of nonmonetary loss and damage.

Acknowledgements The authors wish to thank the Asia-Pacific Network for Global Change Research (APN) for funding the fieldwork of this study. Acknowledgements also go to the Integrated Development Society (IDS) in Nepal for organizing fieldwork logistics. The field team consisted of Sunita Bhattarai, Keshav Paudel, Anjan Kumar Phoju, Ranjita Thapa, Sangita Pokhrel, Ram Krishna Kunwar, Bal Bahadur Gurung, and Maria Kibta. At the United Nations University Institute for Environment and Human Security
(UNU-EHS) Markus Schindler supported with data analysis. This article also greatly benefitted from the comments of two anonymous reviewers.

Open Access This article is distributed under the terms of the Creative Commons Attribution 4.0 International License (http://crea tivecommons.org/licenses/by/4.0/), which permits unrestricted use, distribution, and reproduction in any medium, provided you give appropriate credit to the original author(s) and the source, provide a link to the Creative Commons license, and indicate if changes were made.

\section{References}

Adger, W.N., S. Dessai, M. Goulden, M. Hulme, I. Lorenzoni, D.R. Nelson, L.O. Naess, J. Wolf, and A. Wreford. 2009. Are there social limits to adaptation to climate change? Climatic Change 93(3-4): 335-354.

Agrawala, S., and S. Fankhauser. 2008. Economic aspects of adaptation to climate change: Costs, benefits and policy instruments. Paris: OECD.

Bauer, K. 2013. Are preventive and coping measures enough to avoid loss and damage from flooding in Udayapur district, Nepal? International Journal of Global Warming 5(4): 433-451.

Birkmann, J., O.D. Cardona, M.L. Carreño, A.H. Barbat, M. Pelling, S. Schneiderbauer, S. Kienberger, M. Keiler, D. Alexander, P. Zeil, and T. Welle. 2013. Framing vulnerability, risk and societal responses: The MOVE framework. Natural Hazards 67(2): 193-211.

Blaikie, P., T. Cannon, I. Davis, and B. Wisner. 2003. At risk: Natural hazards, people's vulnerability and disasters. London and New York: Routledge.

Blake, E.S., T.B. Kimberlain, R.J. Berg, J.P. Cangialosi, and J.L. Beven. 2013. Tropical cyclone report Hurricane Sandy (AL182012), 22-29 October 2012. http://www.nhc.noaa.gov/ data/tcr/AL182012_Sandy.pdf. Accessed 17 May 2018.

Boyd, E., R. James, R. Jones, H. Young, and F. Otto. 2017. A typology of loss and damage perspectives. Nature Climate Change 7(10): 723-729.

Burkett, M. 2016. Reading between the red lines: Loss and damage and the Paris outcome. Climate Law 6(1-2): 118-129.

Chambers, R. 1989. Editorial introduction: Vulnerability, coping and policy. IDS Bulletin 20(2): 1-7.

Dahal, R., and S. Hasegawa. 2008. Representative rainfall thresholds for landslides in the Nepal Himalaya. Geomorphology 100(3-4): $429-443$.

Dow, K., F. Berkhout, B.L. Preston, R.J.T. Klein, G. Midgley, and M.R. Shaw. 2013. Limits to adaptation. Nature Climate Change 3(4): 305-307.

van der Geest, K., and M. Schindler. 2016. Case study report: Loss and damage from a catastrophic landslide in Sindhupalchok District, Nepal. Bonn: Institute for Environment and Human Security, United Nations University.

van der Geest, K., and M. Schindler. 2017. Handbook for assessing loss and damage in vulnerable communities. Bonn: United Nations University Institute for Environment and Human Security.

van der Geest, K., and K. Warner. 2015. Vulnerability, coping and loss and damage from climate events. In Hazards, risks and disasters in society, ed. A. Collins, 121-144. New York: Elsevier.

Government of Nepal. 2014. Report on Jure Landslide, Mankha VDC, Sindhupalchowk District. Kathmandu: Ministry of Irrigation. 
Government of Nepal. 2017. Observed climate trend analysis of Nepal (1971-2014). Kathmandu: Department of Hydrology and Meteorology, Ministry of Population and Environment.

Greeley, M. 1994. Measurement of poverty and poverty of measurement. IDS Bulletin 25(2): 50-58.

Huggel, C., J. Clague, and O. Korup. 2012. Is climate change responsible for changing landslide activity in high mountains? Earth Surface Processes and Landforms 37(1): 77-91.

Huggel, C., I. Wallimann-Helmer, D. Stone, and W. Cramer. 2016. Reconciling justice and attribution research to advance climate policy. Nature Climate Change 6(10): 901-908.

IPCC (Intergovernmental Panel on Climate Change). 2012. Managing the risks of extreme events and disasters to advance climate change adaptation. A special report of Working Groups I and II of the Intergovernmental Panel on Climate Change. Cambridge: Cambridge University Press.

James, R., F. Otto, H. Parker, E. Boyd, R. Cornforth, D. Mitchell, and M. Allen. 2014. Characterizing loss and damage from climate change. Nature Climate Change 4(11): 938-939.

Khanal, N.R., and D.R. Gurung. 2014. Results of a rapid investigation of the Jure landslide site on 5 August 2014. http://www.icimod. org/?q=14479. Accessed 17 May 2018.

Kryvasheyeu, Y., H. Chen, N. Obradovich, E. Moro, P. Van Hentenryck, J. Fowler, and M. Cebrian. 2016. Rapid assessment of disaster damage using social media activity. Science Advances 2(3): e1500779.

Kunz, M., B. Mühr, T. Kunz-Plapp, J.E. Daniell, B. Khazai, F. Wenzel, M. Vannieuwenhuyse, T. Comes, F. Elmer, K. Schröter, J. Fohringer, T. Münzberg, C. Lucas, and J. Zschau. 2013. Investigation of superstorm Sandy 2012 in a multi-disciplinary approach. Natural Hazards and Earth System Science 13(10): 2579-2598.

Kusters, K., and N. Wangdi. 2013. The costs of adaptation: Changes in water availability and farmers' responses in Punakha district, Bhutan. International Journal of Global Warming 5(4): 387-399.

Lawson, F. 2017. Climate litigation moves to the private sphere: The case of Lliuya v RWE AG. http://www.6pumpcourt.co.uk/2017/ 12/climate-litigation-moves-to-the-private-sphere-the-case-oflliuya-v-rwe-ag/. Accessed 17 May 2018.

Merz, B., H. Kreibich, R. Schwarze, and A. Thieken. 2010. Assessment of economic flood damage. Natural Hazards and Earth System Science 10(8): 1697-1724.

Mirza, M. 2010. Climate change, flooding in South Asia and implications. Regional Environmental Change 11(S1): S95S107.

Nadiruzzaman, M., and D. Wrathall. 2015. Participatory exclusionCyclone Sidr and its aftermath. Geoforum 64: 196-204.
Parker, H.R., E. Boyd, R.J. Cornforth, R. James, F.E.L. Otto, and M.R. Allen. 2017. Stakeholder perceptions of event attribution in the loss and damage debate. Climate Policy 17(4): 533-550.

Paul, B.K., and S. Dutt. 2010. Hazard warnings and responses to evacuation orders: The case of Bangladesh's cyclone Sidr. Geographical Review 100(3): 336-355.

Roberts, E., K. van der Geest, K. Warner, and S. Andrei. 2014. Loss and damage: When adaptation is not enough. Environmental Development 11: 219-227.

Roberts, E., and S. Huq. 2015. Coming full circle: The history of loss and damage under the UNFCCC. International Journal of Global Warming 8(2): 141-157.

Roberts, E., and M. Pelling. 2016. Climate change-related loss and damage: Translating the global policy agenda for national policy processes. Climate and Development 10(1): 4-17.

Sapkota, B.K. 2017. Landslide loss and damage in Darbung Village, Gorkha District, Nepal. In Climate change research at universities, ed. W.L. Filho, 153-173. Cham, Switzerland: Springer.

Serdeczny, O., E. Waters, and S. Chan. 2016. Non-economic loss and damage: Addressing the forgotten side of climate change impacts. DIE Briefing Paper 03/2016. http://climate-neld.com/ wp-content/uploads/2016/01/BP_3.2016.pdf. Accessed 17 May 2018.

Sharma, E., N. Chettri, K. Tse-Ring, A.B. Shrestha, F. Jing, P. Mool, and M. Eriksson. 2009. Climate change impacts and vulnerability in the Eastern Himalayas. Kathmandu: ICIMOD.

Shrestha, A.B., N.R. Khanal, M. Shrestha, H.K. Nibanupudi, and D. Molden. 2014. Eye on the Sun Koshi landslide: Monitoring and infrastructure planning key to minimizing scale of disasters. http://www.icimod.org/?q=14356. Accessed 17 May 2018.

UNEP (United Nations Environment Programm). 2016. Loss and damage: The role of ecosystem services. Nairobi: UNEP.

Warner, K., and K. van der Geest. 2013. Loss and damage from climate change: Local-level evidence from nine vulnerable countries. International Journal of Global Warming 5(4): 367-386.

Warner, K., K. van der Geest, and S. Kreft. 2013. Pushed to the limit: Evidence of climate change-related loss and damage when people face constrains and limits to adaptation. Bonn: Institute for Environment and Human Security, United Nations University.

Warner, K., K. van der Geest, S. Kreft, S. Huq, S. Harmeling, K. Kusters, and A. de Sherbinin. 2012. Evidence from the frontlines of climate change: Loss and damage to communities despite coping and adaptation. Bonn: Institute for Environment and Human Security, United Nations University. 